\title{
INDIVIDUALISM, COLLECTIVISM, AND GOAL ORIENTATION FOR ATHLETES FROM INDIVIDUAL AND TEAM SPORTS
}

\author{
Polina Hadjiyankova, Tatiana Iancheva \\ National Sports Academy "Vassil Levski", Sofia, Bulgaria
}

\begin{abstract}
OPEN ACCESS
Submitted: 18 November 2021 Revised: 24 November 2021 Accepted: 25 November 2021

ORCID iD

Tatiana Iancheva https://orcid.org/0000-0001-9718-6056 Polina Hadjiyankova https://orcid.org/0000-0002-3291-5323

Cite this article as: Hadjiyankova, P., Iancheva, T. (2021). Individualism, collectivism, and goal orientation for athletes from individual and team sports Journal of Applied Sports Sciences, Vol.2, pp. 66-76. DOI: 10.37393/JASS.2021.02.6

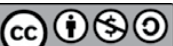

This work is licensed under a Attribution-Non Commercial-ShareAlike 4.0 International (CC BY-NC-SA 4.0)

\section{ABSTRACT}

In the last years, the issue concerning individualism and collectivism in sport has increasingly attracted researchers' attention. The relation between individualism-collectivism and performance has been surveyed (Cox et al., 1991, Mann, 1980, Wagner, 1995), the stability of teamwork (Kiffin-Petersen \& Cordey, 2003, Kirkman, 1996, Kirkman \& Shapiro, 2001), team performance (Karsh, 1984, Smith, 1984).

This study aimed to examine individualism and collectivism and their relation to goal orientation among athletes with different levels of qualification practicing six different kinds of sport. The research was done among 160 athletes practicing six sports - three (3) team sports and three (3) individual sports.

To fulfill the aim of the research, we used: 1 . Scale for measuring the horizontal and vertical individualism and collectivism INDCOL of Singelis, Triandism Bhawuk, \& Gelfand, 1995; 2. Task and Ego Orientation in Sport Questionnaire TEOSQ, Duda \& Nicholls, adapted for Bulgarian conditions by Domuschieva-Rogleva, 2003. 3. Psychological Collectivism Measure-Jackson et al., 2006.

We established significant differences among competitors practicing individual and team sports and differences depending on the qualification, club affiliation, gender. The influence of individualism and collectivism on goal orientation in sport was revealed.
\end{abstract}

Keywords: Individualism, Collectivism, Goal orientation, Ego-orientation, Task-orientation

\section{INTRODUCTION}

In the last twenty years, individualism and collectivism have attracted social scientists' attention - sociologists, anthropologists, and psychologists. Psychologists' great interest has been enhanced due to'Hofstede's research (2011). He explained the intercultural differences with four empirically determining dimensions, one of which was individualism-collectivism. Hofstede pointed out that this dimension is a sociological one, i.e., it explains the peculiarities of the different social environments and the restrictions posed by them on individuals' development. It is not a psychological construct, i.e., it does not serve for comparison and explanation of the behavior of different personalities.

Although the constructs individualism and collectivism are often viewed in literature as the features of different nationalities and cultures, they have also been analyzed as variables on individual-level accounting for the differences among the people belonging to the same nation and culture (Dolan et al., 2004, Eby \& Dobbins, 1997, Kozan \& Ergin, 1999, Schwartz, 1992, Sinha \& Tripathi, 1994, Triandis, 1998, 1989, 1995, Wagner, 1995, Wagner \& Moch 1986). Some authors (Oyserman et al., 2002, 
Triandis, 1995) believe that the construct is made of two semi-independent dimensions. According to them, individualism and collectivism exist as two different dimensions. It is quite possible for a specific athlete to possess both high individualism and high collectivism, i.e., the characteristics do not exclude one another. This debate has led to various research theses and empirical research in this sphere.

The individual differences along the axis of individualism-collectivism are based on selfconcept. Although self-concept is made of numerous identities based on communication with different groups (Stryker, 1980), individualists generally perceive themselves as egocentric and independent. Individualists define themselves as people standing out in the team and view their performance as a result of their individual efforts (Hofstede, 1980, 1991, Triandis, 1980, 1989, 1990). Thus, individualists can be highly motivated by competition, individual rewards, and recognition. They can often work and invest additional efforts to achieve their individual goals (Stone, Romero \& Stone, 2002).

A personality is perceived as an autonomous, independent subject who is self-dependent and different from other people, teams, and subjects. As a result, egocentrics strive to be as independent, autonomous, and self-dependent as possible. They do not have solid bonds with others and feel different from the other team members. In contrast to individualists, collectivists will feel embarrassed if they receive individual recognition. They prefer cooperating to competing, merging with the group to standing out with their personal manifestation.

The research on the relation between individualism-collectivism and performance shows that individualists are a little more cooperative than collectivists in group and team activities (Cox et al., 1991, Mann, 1980, Wagner, 1995).

Some researchers point out that individualism is related to the stability of teamwork (Kiffin-Petersen \& Cordey, 2003, Kirkman, 1996, Kirkman \& Shapiro, 2001). Earley (1998) pointed out that collectivists perform better when they share responsibilities, unlike when they are given individual tasks.

Kirkman et al. (2001) presented a comparison between individualists and collectivists. He revealed that individualists are more stable when working in a team and are less susceptible to the idea that the things they receive are based on team performance. In addition, Gibson and Zellmer-Bruhn (2001) established that individualism limited the range of teamwork expected by the team. On the other hand, due to the importance collectivists attach to shared responsibility, the researchers pointed out that collectivism should help team performance (Karsh, 1984, Smith, 1984).

Wagner (1995) views "individualism-collectivism" as an analytical dimension reflecting the relative importance people attach to personal interests and shared goals. Individualists attach more meaning and importance to their personal goals than to the team's needs. They take care of themselves and ignore the team's interests when contrasted with their personal interests. According to this perception, collectivism is the opposite of individualism (Hui, 1998, Oyserman et al., 2002).

In a broad sense, in sport, collectivism presents the border to which different individuals are oriented in their group (team) goals. Such individuals are concerned for the well-being of 
their teammates, accept group norms, and tend to cooperate in the group (team) (Triandis, 1995, Wagner, 1995, Wagner \& Moch, 1986).

Because of these reasons, collectivism is viewed as a logical research construct due to its influence on teams' functionality. The surveys show that in teams consisting of persons with a high level of collectivism, competitors give each other more emotional, informative, and sustaining support compared to other teams consisting of athletes with a low level of collectivism (Drack-Zahavy, 2004).

The ratio among the players with high and low levels of collectivism on a team is directly related to the cooperation in the team (Eby \& Dobbins, 1997).

Jackson (Jackson et al., 2006) described five specific aspects of collectivism: Preference, Concern, Hope, Acceptance of norms, Prioritization of goals.

Collectivists view team interests as more important than individual needs and desires. They tend to take care of the well-being of the team they belong to even when such actions lead to sacrificing their personal interests (Wagner \& Moch, 1986).

For the aims of this research, we focused on the variable individualism-collectivism on an individual level, which perceives individualism and collectivism as opposite characteristics. The surveys of Ramamoorthy and Flood (2002, 2004) revealed that whether one is an individualist or a collectivist is determined by one's preferences for individual work, personal goals, competitiveness, and autonomy.

Individualism and collectivism are constructs we can trace both in individual and team sports. We can assume that athletes with more expressed collectivism and more weakly expressed individualism can be found more often in team sports. However, whether this is so or not, does it mean that when people practice a team sport, they are more collectivist than individualists and vice versa?

A sports team is a union of athletes who have both personal and shared tasks to achieve a mutual sports result. The common goal and the everyday tasks turn a sports team into a collective subject of sports activity.

The sports environment stimulates the process of self-identification both on an individual and on a group level. Identity stirs security, stability of behavior, and the ability for integrity.

The scientific information on the issue of individualism and collectivism in sport in the literature we know about is still scarce. Few authors have viewed this issue theoretically and empirically, and even fewer are willing to engage themselves with a particular stable concept.

We are interested in the relation among the constructs of individualism and collectivism and goal orientation in sport. According to the theory of goal orientation in sport (Duda, 1989), when there is a high task orientation, success is determined as a result of improvement in skills, self-perfection, positive and adaptive behavior aimed at achievements. Ego orientation is related to behavior aimed at domineering, superiority or obedience, comparing one's own abilities with those of the others. Nicholls's goal theory of achievement $(1984,1989)$ supposes that achieving the goal and demonstrating abilities are significant motivation incentives in the context of achievements. The representatives of this theory have outlined two concepts for 
competence which are manifested through the two conditions - task purpose or ego purpose. When the participation is because of the task, the perceived ability is related to itself. The emphasis is on mastery, effort investment, development of skills, or gaining knowledge about the activity. When ego dominates, persons show a high ability compared to the norms. In this case, the ability is demonstrated when one's performance surpasses that of the others or is done equally well but with fewer efforts (Nicholls, 1984, 1989).

This study aimed to examine individualism and collectivism and their relation to goal orientation among athletes with different levels of qualification practicing six different kinds of sports.

\section{MATERIALS AND METHODS}

\section{Participants}

The research was done among 160 athletes from six different sports -3 team sports (football, basketball, volleyball) and 3 individual sports (tennis, swimming, rowing), from 8 clubs and 1 national team. Of them, 110 men and 50 women aged between 16 and 35 years. For the research purpose, the competitors were divided into two groups depending on their qualification - athletes competing for the national team and athletes belonging to a club.

At the beginning of the research, all participants were informed about the survey's aim, and their consent was obtained.

We assume that there are certain differences regarding individualism and collectivism among athletes practicing individual and team sports and differences depending on their level of qualification. We suppose there are specific differences in the goal orientation of players with a dominant individualism or collectivism.

\section{Instruments}

To fulfill the aim of the research, we used complex methods including:

Scale for measuring the horizontal and vertical individualism and collectivism INDCOL of Singelis, Triandism Bhawuk, \& Gelfand, 1995. The scale consists of four subscales:

- Horizontal individualism (HI) - the desire to be unique, to stand out in a group, to rely only on yourself;

- Vertical individualism (VI) - the desire to be different and recognizable due to your personal merits and wins;

- Horizontal collectivism (HC) - the desire to be uniform with others, to belong to and depend on the group;

- Vertical collectivism (VC) - the desire for affiliation and mutual success in the group but attaching a tremendous significance to the family and its expectations.

The vertical scale emphasizes the hierarchy while the horizontal one emphasizes equality in relationships.

Task and Ego Orientation in Sport Questionnaire - TEOSQ, Duda \& Nicholls, 1992 (Castillo et al., n.d.), adapted for Bulgarian conditions by Domuschieva-Rogleva, 2003. The test consists of 13 items and a 5-point Likert-type scale to evaluate the degree of their expressiveness. It measures the factors task orientation and ego orientation.

Psychological Collectivism Measure - Jackson et. al., 2006. The scale consists of 15 items, assessed with a 5-point Likert type scale. It mea- 
sures the degree of collectivism inside a team.

The scales show very good psychometric characteristics in Bulgarian conditions.

\section{Statistical Analysis}

When processing the initial data from the research, we used the statistical package SPSS 21 and made a variation, correlation, comparative, and regression analyses.

All participants were informed about the research aim and granted their agreement.

The research was held in the period March-July in actual conditions.

\section{RESULTS AND ANALYSIS}

The obtained results revealed that horizontal collectivism's scale received the highest values $(M=3.94)$. It reflects the strong desire for affiliation to the group and mutual dependence (Table 1). Next was the scale horizontal individualism $(M=3.87)$, related to the desire to be unique, stand out in the group, and rely on yourself. We were rather impressed by the low values of the vertical scales - vertical collectivism $(M=3.34)$ and vertical individualism $(M=3.31)$, i.e., the scales related to hierarchy.

We were surprised by the obtained results related to the research of goal orientation. The results from this survey showed that ego orientation was the leading one $(M=3.61)$. The mean value for the task orientation was $M=$ 3.43. These results differ from those obtained in other surveys of ours (Iancheva, Kuleva, 2017; Iancheva, 2019) and some data in the literature.

Table 1. Results from descriptive statistics

\begin{tabular}{lcccccc}
\hline & $\mathbf{N}$ & $\mathbf{M}$ & SD & Min & Max & Variance \\
\hline Horizontal individualism & 160 & 3.8663 & .65172 & 1.10 & 5.00 & .425 \\
Vertical individualism & 160 & 3.3106 & .64160 & 1.00 & 4.70 & .412 \\
Horizontal collectivism & 160 & 3.9438 & .70405 & 1.00 & 5.00 & .496 \\
Vertical collectivism & 160 & 3.3350 & .62215 & 1.00 & 4.70 & .387 \\
Collectivism & 160 & 3.6881 & .78743 & .60 & 5.00 & .620 \\
Task Orientation & 160 & 3.4319 & .72306 & 1.00 & 5.70 & .523 \\
Ego Orientation & 160 & 3.6106 & .59427 & 1.00 & 5.00 & .353 \\
Age & 160 & 18.4688 & 4.56941 & 16.00 & 35.00 & 20.880 \\
\hline
\end{tabular}

The data from the comparative analysis of the results of the athletes practicing individual and team sports revealed statistically significant differences along three of the researched parameters (Table 2) - horizontal collectivism, degree of collectivism in the team, and task orientation. Our expectations were confirmed
- the representatives of the team sports possessed significantly higher collectivist attitudes. The athletes practicing individual sports were characterized with a more strongly expressed task orientation, i.e., mastery through investing efforts and development of skills and knowledge. 
Table 2. Results from the comparative analysis of athletes practicing individual and team sports

\begin{tabular}{lrrrrrrr}
\hline & \multicolumn{1}{c}{ HI } & \multicolumn{1}{c}{ VI } & \multicolumn{1}{c}{ HC } & \multicolumn{1}{c}{ VC } & \multicolumn{1}{c}{ COLL } & \multicolumn{1}{c}{ TASK } & \multicolumn{1}{c}{ EGO } \\
\hline Mann-Whitney U & 2506.000 & 2903.000 & 1538.000 & 2681.000 & 1859.500 & 2277.500 & 2480.500 \\
Wilcoxon W & 7556.000 & 4733.000 & 3368.000 & 4511.000 & 3689.500 & 7327.500 & 7530.500 \\
Z & -1.744 & -.344 & -5.163 & -1.132 & -4.025 & -2.550 & -1.838 \\
Asymp. Sig. (2-tailed) & .081 & .731 & .000 & .258 & .000 & .011 & .066 \\
\hline
\end{tabular}

Legend: HI - Horizontal individualism, VI - Vertical individualism, HC - Horizontal collectivism, VC - Vertical collectivism, Collectivism, Task Orientation, Ego Orientation

The obtained results revealed significant nificantly higher values along the three subdifferences along the factor gender and three scales among the men, i.e., a greater aspiration of the researched indicators - horizontal and for affiliation and success in the team, mutual vertical collectivism and degree of collectiv- dependence on the group. ism in the team (Table 3 ). We established sig-

Table 3. Results from the comparative analysis along with the factor gender

\begin{tabular}{lrrrrrrr}
\hline & \multicolumn{1}{c}{ HI } & \multicolumn{1}{c}{ VI } & \multicolumn{1}{c}{ HC } & \multicolumn{1}{c}{ VC } & COLL & \multicolumn{1}{c}{ TASK } & \multicolumn{1}{c}{ EGO } \\
\hline Mann-Whitney U & 2440.000 & 2349.000 & 1493.000 & 2050.500 & 1710.500 & 2682.500 & 2411.000 \\
Wilcoxon W & 3766.000 & 3675.000 & 2819.000 & 3376.500 & 3036.500 & 4008.500 & 8406.000 \\
Z & -1.245 & -1.585 & -4.720 & -2.687 & -3.919 & -.356 & -1.354 \\
Asymp. Sig. (2-tailed) & .213 & .113 & .000 & .007 & .000 & .722 & .176 \\
\hline
\end{tabular}

The results from the comparative analysis depending on club affiliation were quite interesting. The data revealed significant differences along all scales measuring individualism and collectivism (Table 4). The specific sports environment and the management style probably influence the researched indicators.

Table 4. Results from the comparative analysis depending on the club affiliation

\begin{tabular}{lcccccc}
\hline & HI & VI & HC & VC & COLL & TASK \\
\hline Chi-Square & 13.223 & & & & & \\
df & 5 & 5 & 5 & 5 & 5 & 5 \\
Asymp. Sig. & .021 & .021 & .007 & .004 & .001 & .120 \\
\hline
\end{tabular}

Legend: HI - Horizontal individualism, VI - Vertical individualism, HC - Horizontal collectivism, VC - Vertical collectivism, Collectivism, Task Orientation, Ego Orientation

The comparative analysis of the data results showed dependence on the qualification. The athletes competing for the national teams had higher values of vertical individualism (VI), (Table 5). 
Table 5. Results from the comparative analysis depending on qualification

\begin{tabular}{lrrrrrrr}
\hline & \multicolumn{1}{c}{ HI } & \multicolumn{1}{c}{ VI } & \multicolumn{1}{c}{ HC } & \multicolumn{1}{c}{ VC } & \multicolumn{1}{c}{ COLL } & \multicolumn{1}{c}{ TASK } & \multicolumn{1}{c}{ EGO } \\
\hline Mann-Whitney U & 2120.500 & 1541.500 & 1979.500 & 1962.500 & 1759.500 & 1981.500 & 1853.500 \\
Wilcoxon W & 9870.500 & 9291.500 & 2645.500 & 2628.500 & 2425.500 & 2647.500 & 9603.500 \\
Z & -.456 & -2.836 & -1.034 & -1.108 & -1.933 & -1.025 & -1.552 \\
Asymp. Sig. (2-tailed) & .648 & .005 & .301 & .268 & .043 & .305 & .121 \\
\hline
\end{tabular}

Legend: HI - Horizontal individualism, VI - Vertical individualism, HC - Horizontal collectivism, VC - Vertical collectivism, Collectivism, Task Orientation, Ego Orientation

Table 6. Results from the comparative analysis depending on the qualification of the athletes practicing team sports

\begin{tabular}{lrrrrrrr}
\hline & HI & \multicolumn{1}{c}{ VI } & \multicolumn{1}{c}{ HC } & \multicolumn{1}{c}{ VC } & COLL & \multicolumn{1}{l}{ TASK } & \multicolumn{1}{c}{ EGO } \\
\hline Mann-Whitney U & 2120.500 & 1541.500 & 1979.500 & 1962.500 & 1759.500 & 1981.500 & 1853.500 \\
Wilcoxon W & 9870.500 & 9291.500 & 2645.500 & 2628.500 & 2425.500 & 2647.500 & 9603.500 \\
Z & -.456 & -2.836 & -1.034 & -1.108 & -1.933 & -1.025 & -1.552 \\
Asymp. Sig. (2-tailed) & .648 & .005 & .301 & .268 & .043 & .305 & .121 \\
\hline
\end{tabular}

Legend: HI - Horizontal individualism, VI - Vertical individualism, HC - Horizontal collectivism, VC - Vertical collectivism, Collectivism, Task Orientation, Ego Orientation

The group of the athletes practicing indi- The athletes with a higher level of qualificavidual sports had significant differences in the tion had significantly more weakly expressed degree of collectivism in the team (Table 7). collectivist attitudes.

Table 7. Results from the comparative analysis depending on the qualification of the athletes practicing individual sports

\begin{tabular}{lrrrrrrr}
\hline & \multicolumn{1}{c}{ HI } & \multicolumn{1}{c}{ VI } & \multicolumn{1}{c}{ HC } & \multicolumn{1}{c}{ VC } & \multicolumn{1}{c}{ COLL } & \multicolumn{1}{c}{ TASK } & \multicolumn{1}{c}{ EGO } \\
\hline Mann-Whitney U & 240.000 & 259.000 & 253.000 & 233.500 & 110.000 & 248.000 & 188.000 \\
Wilcoxon W & 1465.000 & 1484.000 & 319.000 & 299.500 & 176.000 & 1473.000 & 1413.000 \\
Z & -.565 & -.201 & -.316 & -.691 & -3.054 & -.411 & -1.562 \\
Asymp. Sig. (2-tailed) & .572 & .840 & .752 & .490 & .002 & .681 & .118 \\
\hline
\end{tabular}

Legend: HI - Horizontal individualism, VI - Vertical individualism, HC - Horizontal collectivism, VC - Vertical collectivism, Collectivism, Task Orientation, Ego Orientation

Table 8. Results from regression analysis

\begin{tabular}{lcccc}
\hline & $\boldsymbol{\beta}$ & $\mathbf{t}$ & $\mathbf{S i g}$ & $\mathbf{\Delta R}^{\mathbf{2}}$ \\
\hline Horizontal individualism & & & & \\
Ego orientation & .336 & 4.653 & .000 & .161 \\
Vertical individualism & .272 & 3.778 & .000 & .231 \\
\hline
\end{tabular}

Vertical individualism 


\begin{tabular}{lcccc} 
Horizontal individualism & .314 & 4.365 & .000 & .125 \\
Vertical individualism & .284 & 3.950 & .000 & .204 \\
\hline Horizontal collectivism & & & & \\
Collectivism & .531 & 8.03 & .000 & .408 \\
Vertical collectivism & .223 & 3.263 & .001 & .462 \\
Task orientation & .129 & 2.137 & .034 & .477 \\
\hline Vertical collectivism & & & & \\
Horizontal collectivism & .261 & 3.016 & .003 & .255 \\
Vertical individualism & .186 & 2.747 & .007 & .302 \\
Collectivism & .269 & 3.178 & .002 & .337 \\
Task orientation & .147 & 2.168 & .032 & .357 \\
\hline Collectivism & & & & \\
Horizontal collectivism & .552 & 8.038 & .000 & .408 \\
Vertical collectivism & .228 & 3.287 & .001 & .438 \\
Task orientation & -.143 & -2.330 & .021 & .457 \\
\hline
\end{tabular}

\section{DISCUSSION}

The results from the research we carried out confirmed our initial hypothesis that there are certain differences regarding individualism and collectivism among athletes practicing individual and team sports, as well as differences depending on the level of qualification. The data obtained from the athletes practicing individual and team sports revealed statistically significant differences along three of the researched indicators - horizontal collectivism, degree of collectivism in the team, and task orientation. Our expectations that the athletes practicing team sports have significantly higher collectivist attitudes were confirmed. The athletes practicing individual sports are characterized with a more strongly expressed task orientation, i.e., mastery and achieving results through investing efforts, developing skills, and gaining knowledge.

The results from the comparative analysis of the data depending on qualification did not fully confirm our initial expectations. The athletes who compete for the national teams showed significantly higher values along the vertical individualism scale. They had a higher aspiration to be different and recognizable because of their own achievements and merits. After the additional analyses made for each group - individual and team sports, we found that the competitors practicing individual sports, with higher levels of qualification, had significantly more weakly expressed collectivist attitudes. These results were to be expected and confirmed the data found in literature (Hofstede, 1980, 1991, Triandis, 1980, 1989, 1990). The athletes with a higher level of qualification, practicing team sports, had significantly higher values of vertical individualism. They seek recognition and want to stand out on the basis of their efforts and the achieved level of development, i.e., we can assume that the more successful competitors, whether they are representatives of individual or team sports, possess a more strongly expressed individualism. 
There were significant differences along all scales of individualism and collectivism depending on club affiliation. The specific sports environment and the coach's management style probably influenced the researched indicators. These results will require further research and analyses.

There were significant gender differences along all scales of collectivism. Men have a more strongly expressed aspiration for affiliation, dependence, and success on the team, regardless of the kind of sport they practice.

We found the results from the research of goal orientation surprising. Ego orientation was dominant in our sample, which differs from the findings in our previous studies (Iancheva, Kuleva, 2017, Iancheva, 2019).

The obtained results from the regression analysis regarding the relation among individualism, collectivism, and goal orientation in sports, make us assume that individualism and collectivism affect goal orientation in sports. Horizontal individualism stimulates ego orientation. Horizontal and vertical collectivism can forecast task orientation, the degree of collectivism in the team, and can stimulate task orientation.

\section{LIMITATIONS}

This research has a few limitations - the number of the researched sample and the number of the researched sports. A broader scope of research would allow for more in-depth analysis and interpretation.

\section{REFERENCES}

Cox T., Blake S. (1991). Managing cultural diversity: Implications for organizational com- petitiveness. Academy of Management Executive, 5(3), pp. 45-56.

Cox, H. (1985). Sport psychology: Concepts and application. Dubuque, IA: Wm. C. Brown.

Dolan, S.L., Díez-Piñol, M., Fernández-Alles, M.L., Martín-Prius, A. \& Martínez-Fierro, S. (2004). Exploratory study of within-country differences in work and life values: The case of Spanish business students . International Journal of Cross Cultural Management, 4, pp. 157-181.

Domuschieva-Rogleva, G. (2003). Aprobacia na testa za orientacia kum zadachata I kum sebe si (TEOSQ) v bulgarski uslovia, Lichnost, motivacia, sport, T. 9, S., NSA PRESS, 65-71 (In Bulgarian)// ДомусчиеваРоглева, Г. (2003). Апробация на теста за ориентация към задачата и към себе си (TEOSQ) в български условия. - В: Личност, мотивация, спорт. Т. 9, С., НСА ПРЕС, pp. 65-71.

Duda, J. L. (1989). Relationship between Task and Ego Orientation and the Perceived Purpose of Sport among High School Athletes, Journal of Sport and Exercise Psychology, 11(3), pp. 318-335.

Duda, J. L., \& Nicholls, J. G. (1992). Dimensions of achievement motivation in schoolwork and sport. Journal of Educational Psychology, 3.

Eby, L. T., \& Dobbins, G. H. (1997). Collectivistic orientation in teams: An individual and group-level analysis. Journal of Organizational Behavior, 18(3), pp. 275-295.

Gibson, C. B., \& Zellmer-Bruhn, M. E. (2001). Metaphors and Meaning: An Intercultural Analysis of the Concept of Teamwork. 
Administrative Science Quarterly, 46(2), pp. 274-303.

Hofstede, G. (1980). Culture's consequences: International differences in work-related values. Beverly Hills, CA, Sage.

Hofstede, G. (1996). Riding the waves of commerce: A test to Trompenaars „model““ of national culture differences. International Journal of Intercultural Relations, 20, 2, pp. 189-198.

Hofstede, G. (2001). Kultura I organizacii. Softuer na uma. Mejdukulturnoto sutrudnichestvo I znachenieto $\mathrm{mu}$ za ocelyavaneto. Sofia (In Bulgarian) // Хофстеде, X. (2001) Култури и организации. Софтуер на ума. Междукултурното сътрудничество и значението му за оцеляването. София.

Hofstede, G. (2011). Dimensionalizing Cultures. The Hofstede Model in Context. Cross-Cultural Research, 38, pp. 52-88.

Iancheva, T. (2019). Parents in Sport. Parent-initiated Motivational climate and Goal orientation in Sport, International Scientific Congress "Applied Sports Sciences", Balkan Scientific Congress "Physical Education, Sports, Health", S., NSA Press, pp. 249-254.

Iancheva, T., M. Kuleva, (2017). Goal orientation and cope with success in sport, International Scientific Congress "Applied Sports Sciences", Proceeding book, S., NSA Press, pp. 218-223.

Jackson, C. L., Colquitt, J. A., Wesson, M. J., \& Zapata-Phelan, C. P. (2006). Psychological collectivism: A measurement validation and linkage to group member performance. Journal of Applied Psychology, 91(4), pp. 884-899.

Karsh, B. (1984). Human resource management in Japanese large-scale industry. Journal of Industrial Relations, 26, pp. 226-45.

Kiffin-Petersen, S., \& Cordery, J. (2003). Trust, individualism, and job characteristics as predictor of employee preference for teamwork. Human Resource Management, 14, pp. 96-116.

Kirkman, B. L. (1996). The impact of national culture on employee resistance to teams: A comparative analysis of globalized self-managing work team effectiveness between the United States, Finland, and the Philippines.

Kirkman, B. L., \& Shapiro, D. L. (2001). The Impact of Team Members' Cultural Values on Productivity, Cooperation, and Empowerment in Self-Managing Work Teams. Journal of Cross-Cultural Psychology, 32(5), pp. 597-617.

Kozan, M. and Ergin, C. (1999), The influence of intra-cultural value differences on conflict management practices, International Journal of Conflict Management, Vol. 10 No. 3, pp. 249-267.

Nicholls, G. (1989). The Competitive and Democratic Education, Cambridge, MA, Harvard University Press.

Oyserman, D., Coon, H. M., \& Kemmelmeier, M. (2002). Rethinking individualism and collectivism: Evaluation of theoretical assumptions and meta-analyses. Psychological Bulletin, 128(1), pp. 3-72.

Ramamoorthy, N. \& Flood, P. (2002). Employee attitudes and behavioral intentions: A test of the main and moderating effects of individualism-collectivism orientations, Human Relations, 55, pp. 1071-1096.

Singelis, T. M., Triandis, H. C., Bhawuk, D. P. S., Gelfand, M. J. (1995). Horizontal and vertical dimensions of individualism and 
collectivism: A theoretical and measurement refinement. Cross-Cultural Research, 29, pp. 240-275.

Sinha, D., \& Tripathi, R.C. (1994). Individualism in a collectivist culture: A case of coexistence of opposites. In U. Kim, H.C. Triandis, C. Kagitcibasi, S.C. Choi, \& G. Yoon (Eds.). Individualism and collectivism: Theory, method, and applications. Thousand Oaks, CA. Sage, pp. 123-36.

Smith, J. (1984). Labour Tradition in Glasgow and Liverpool. History Workshop, 17, pp. 32-56.

Stone-Romero, E.F. \& Stone, D.L. (2002), Cross-cultural differences in responses to feedback: Implications for individual, group, and organizational effectiveness, Research in Personnel and Human Resources Management, Vol. 21, Emerald Group Publishing Limited, Bingley, pp. 275-331.

Stryker, S. (1980). Symbolic Interactionism. Menlo Park, CA: Benjamin/ Cummings.

Triandis, H. (1998). Converging measurement of horizontal and vertical individualism and collectivism. Journal of Personality and Social Psychology, 74, pp. 118-128.

Triandis, H. (2001). Individualism-collectivism and personality. Journal of Personality, 69, 6, pp. 908-924.
Triandis, H. (2004). The many dimensions of culture. Academy of Management Executive, 18, 1, pp. 88-93.

Triandis, H. C. (1989). The self and social behavior in differing cultural contexts. Psychological Review, 96(3), pp. 506-520.

Triandis, H. C. (1995). Individualism and collectivism. Boulder, CO: Westview Press.

Triandis, H. C., Chen, X. P., \& Chan, D. K.-S. (1998). Scenarios for the Measurement of Collectivism and Individualism. Journal of Cross-Cultural Psychology, 29(2), pp. 275289.

Wagner III, J., Humphrey, S., Meyer, C. Hollenbeck. J. Individualism-collectivism and team performance: Another look. Journal of Organizational Behavior, 33, 7, pp. 946-963.

Wagner, J. A., III, \& Moch, M. K. (1986). Individualism- collectivism: Concept and measure. Group and Organization Studies, 11, pp. $280-304$.

Wagner, J. A., III. (1995). Studies of individualism-collectivism: Effects on cooperation in groups. Academy of Management Journal, 38, pp. 152- 172 .

Waldman, D. A. (1997). Predictors of employee preferences for multi-rater and groupbased performance appraisal. Group and Organization Management, 22, pp. 264 -287.

\section{Corresponding author:}

Tatiana Iancheva

Psychology, Pedagogy, Sociology Department National Sports Academy "Vassil Levski" 21, Acad. Stefan Mladenov, str. Sofia, Bulgaria E-mail: iancheva.tatiana@gmail.com 